\title{
Relationship between visual field progression and baseline refraction in primary open-angle glaucoma
}

This article was published in the following Dove Press journal:

Clinical Ophthalmology

28 July 2016

Number of times this article has been viewed

\author{
Tomoko Naito' \\ Keiji Yoshikawa ${ }^{2}$ \\ Shiro Mizoue ${ }^{3}$ \\ Mami Nanno ${ }^{4}$ \\ Tairo Kimura ${ }^{5}$ \\ Hirotaka Suzumura ${ }^{6}$ \\ Yuzo Umeda ${ }^{7}$ \\ Fumio Shiraga' \\ 'Department of Ophthalmology, \\ Okayama University Graduate \\ School of Medicine, Okayama, Japan; \\ ${ }^{2}$ Yoshikawa Eye Clinic, Tokyo, Japan; \\ ${ }^{3}$ Department of Ophthalmology, \\ Ehime University Graduate \\ School of Medicine, Ehime, Japan; \\ ${ }^{4}$ Kagurazaka Minamino Eye Clinic, \\ ${ }^{5}$ Ueno Eye Clinic, ${ }^{6}$ Suzumura Eye \\ Clinic, Tokyo, Japan; ${ }^{7}$ Department of \\ Gastroenterological Surgery, Okayama \\ University Graduate School of \\ Medicine, Okayama, Japan
}

Correspondence: Tomoko Naito

Department of Ophthalmology,

Okayama University Graduate School

of Medicine, 2-5-I Shikata-cho, Kita-ku,

Okayama 700-8558, Japan

$\mathrm{Tel}+8 \mathrm{I} 862357297$

Fax +8I 862225059

Email tomokoum@gmail.com
Purpose: To analyze the relationship between visual field (VF) progression and baseline refraction in Japanese patients with primary open-angle glaucoma (POAG) including normaltension glaucoma.

Patients and methods: In this retrospective study, the subjects were patients with POAG who had undergone VF tests at least ten times with a Humphrey Field Analyzer (Swedish interactive thresholding algorithm standard, Central 30-2 program). VF progression was defined as a significantly negative value of mean deviation (MD) slope at the final VF test. Multivariate logistic regression models were applied to detect an association between MD slope deterioration and baseline refraction.

Results: A total of 156 eyes of 156 patients were included in this analysis. Significant deterioration of MD slope was observed in 70 eyes of 70 patients (44.9\%), whereas no significant deterioration was evident in 86 eyes of 86 patients $(55.1 \%)$. The eyes with VF progression had significantly higher baseline refraction compared to those without apparent VF progression ( $-1.9 \pm 3.8$ diopter $[\mathrm{D}]$ vs $-3.5 \pm 3.4 \mathrm{D}, P=0.0048$ ) (mean \pm standard deviation). When subject eyes were classified into four groups by the level of baseline refraction applying spherical equivalent (SE): no myopia $(\mathrm{SE}>-1 \mathrm{D})$, mild myopia $(-1 \mathrm{D} \geq \mathrm{SE}>-3 \mathrm{D})$, moderate myopia $(-3 \mathrm{D} \geq \mathrm{SE}>-6 \mathrm{D})$, and severe myopia ( $-6 \mathrm{D} \geq \mathrm{SE}$ ), the Cochran-Armitage trend analysis showed a decreasing trend in the proportion of MD slope deterioration with increasing severity of myopia $(P=0.0002)$. The multivariate analysis revealed that baseline refraction $(P=0.0108$, odds ratio [OR]: $1.13,95 \%$ confidence interval [CI]: $1.03-1.25)$ and intraocular pressure reduction rate $(P=0.0150, \mathrm{OR}$ : 0.97, 95\% CI: 0.94-0.99) had a significant association with MD slope deterioration.

Conclusion: In the current analysis of Japanese patients with POAG, baseline refraction was a factor significantly associated with MD slope deterioration as well as intraocular pressure reduction rate. When baseline refraction was classified into four groups, MD slope in myopia groups was less deteriorated as compared to those in the emmetropic/hyperopic group.

Keywords: primary open-angle glaucoma, normal-tension glaucoma, myopia, refraction, visual field progression, MD slope, intraocular pressure reduction rate

\section{Introduction}

Several epidemiologic studies have focused on the relationship between myopia and development of open-angle glaucoma (OAG). ${ }^{1-12}$ In the Tajimi Study, ${ }^{8}$ myopia (odds ratio [OR]: 1.85, 95\% confidence interval [CI]: 1.03-3.31 for low myopia; OR: 2.60, 95\% CI: $1.56-4.35$ for moderate to high myopia) as well as higher intraocular pressure (IOP) (OR: 1.12, 95\% CI: 1.04-1.21) and older age (OR: 1.06, 95\% CI: 1.04-1.08) were identified as significant risk factors for having primary open-angle glaucoma (POAG). 
A meta-analysis of myopia as a risk factor for OAG, which combined data from eleven population-based cross-sectional studies, also found a pooled OR of 1.92 (95\% CI: $1.54-2.38)^{4}$ and concluded that patients with myopia have an increased risk of developing OAG.

On the other hand, there is controversy with regard to whether myopia is a risk factor for visual field (VF) progression in OAG. Several studies have reported that myopia is a risk factor for the progression. ${ }^{13-15}$ In contrast, a couple of studies have reported that myopia is not a risk factor ${ }^{16-18}$ or that myopia is even a preventive factor for VF progression in OAG. ${ }^{19-21}$ In Japan, the majority of glaucoma is POAG, particularly normal-tension glaucoma (NTG). ${ }^{22,23}$ The prevalence of myopia is also high in Japan. ${ }^{24}$ Understanding the relationship between myopia and VF progression in POAG may be a clue to proceed with intensive treatment.

Hence, the aim of this analysis was to analyze the association between baseline refraction and VF progression by utilizing the longitudinal data of our retrospective observational study. ${ }^{25}$ Furthermore, we divided the subject eyes into four myopia groups by baseline refraction and analyzed the association between myopia and VF progression.

\section{Patients and methods}

\section{Study design}

This was a multicenter, retrospective, observational study.

\section{Subjects}

The subjects in this analysis were based on our previous study data. ${ }^{25}$ The protocol for this study was approved in advance by the Institutional Review Board of Nihonmatsu Eye Hospital. Informed consent was obtained from the subjects after a thorough explanation of the study objective and information collection was given in accordance with ethical principles based on the Helsinki Declaration. Test data were collected separately by each participating facility. Briefly, all subjects were patients with POAG or NTG, and one eye from each subject which met the inclusion criteria and did not fulfill the exclusion criteria was selected. If both eyes met the inclusion criteria, the eye with the lower initial mean deviation (MD) value was selected for analysis.

The inclusion criteria for this study were: 1 ) age $\geq 20$ years; 2) obvious glaucomatous VF defects in accordance with Anderson's criteria; ${ }^{26} 3$ ) Grade 3-4 Shaffer's grade of anterior chamber angle ${ }^{27}$ (angle width $20^{\circ}-45^{\circ}$ ); 4) VF tests with a Humphrey Field Analyzer (Zeiss-Humphrey Systems, San Leandro, CA, USA) a total of ten times or more, in principle, every 6 months without alteration in strategy (Swedish interactive thresholding algorithm standard) or program (C30-2);
5) ability to measure MD slope by using HfaFiles (Beeline, Tokyo, Japan); 6) baseline IOP measured at least three times applying a Goldmann applanation tonometer before undergoing treatment; and 7) IOP measured regularly (every 3 months in principle) during the follow-up period.

The exclusion criteria were as follows: 1) MD $<-20 \mathrm{~dB}$ on initial VF test; 2 ) corrected visual acuity (decimal visual acuity) during the follow-up period $<0.7$; 3) any catch trials of VF test (fixation loss, false positives, and false negatives) $\geq 33 \%$; 4) presence of an ophthalmic disorder other than glaucoma affecting the VF, such as temporal VF defects, Mariotte blind spot expansion, and VF defects by myopic changes in the macular region; 5) previous ophthalmic surgery (including intraocular lens implantation) during the follow-up period; 6) nonphakic eyes; 7) abnormalities of the anterior segment disturbing accurate Goldmann applanation tonometer measurements; 8) history of recurrent uveitis, scleritis, or corneal herpes; 9) pregnancy or lactation; 10) severe dementia or serious ophthalmic conditions; or 11) judged by an investigator to be ineligible to participate in this study.

Sex was not considered, and there were no restrictions on the type of glaucoma eye drops prescribed for treatment.

\section{Procedure}

The primary analysis was to assess interaction between VF progression and baseline refraction. VF progression was defined as the presence of a significantly negative value of MD slope $(P<0.05)$ at the final VF test. The MD value and MD slope were calculated using HfaFiles. The Auto Kerato-Refractometer was used to measure the degree of refraction. By referring to the classification used in the Tajimi study, ${ }^{8}$ baseline refraction of each subject eye was divided into four groups according to the level of spherical equivalent (SE): emmetropia/hyperopia $(\mathrm{SE}>-1$ diopter [D]), mild myopia ( $-1 \mathrm{D} \geq \mathrm{SE}>-3 \mathrm{D})$, moderate myopia $(-3 \mathrm{D} \geq \mathrm{SE}>-6 \mathrm{D})$, and severe myopia $(-6 \mathrm{D} \geq \mathrm{SE})$ group. Baseline IOP was defined by calculating the mean value of three IOP measurements before glaucoma treatment. The mean of all IOP values measured during the follow-up period after the start of treatment was regarded as the mean IOP in this study. The difference between baseline IOP and mean IOP was defined as $\triangle \mathrm{IOP}$, and the proportion of $\triangle \mathrm{IOP}$ of baseline IOP was taken as the reduction rate of IOP. Long-term IOP fluctuation was calculated as the standard deviation of IOP measurements over the follow-up period. In the present study, the mean of the highest and secondhighest IOP, as well as the lowest and second-lowest IOP, was defined as the maximum IOP and the minimum IOP, respectively. 


\section{Statistical analysis}

Data analysis was performed independently at the Department of Gastroenterological Surgery, Okayama University, Japan. A $t$-test or Fisher's exact test was used for the analysis of each factor, depending on the data scale concerned. One-way analysis of variance was applied to explore potential factors associated with MD slope deterioration. Multivariate logistic regression models were applied to detect the significant association between explanatory variables and MD slope deterioration as an objective variable. OR with $95 \% \mathrm{CI}$ were calculated in the final multivariate analysis. All variables were selected as nonmulticollinearity after employment of variables' correlation coefficient less than 0.3 . The analytical software used was JMP version 9.0 (SAS Institute Inc., Cary, NC, USA), and the level of significance was set at $5 \%$ on both sides.

\section{Results}

A total of 156 eyes of 156 patients (94 females $(60.3 \%$ ) and 62 males $(39.7 \%))$ were included for the analysis (Table 1$).{ }^{25}$ The mean age was $64.6( \pm 12.9$ years [standard deviation $\{\mathrm{SD}\}])$. The type of glaucoma was NTG in 141 eyes $(90.4 \%)$ and POAG in 15 eyes $(9.6 \%)$. Baseline refraction was $-2.8 \pm 3.7 \mathrm{D}$, baseline IOP was $16.6 \pm 3.7 \mathrm{mmHg}$, initial MD was $-7.08 \pm 4.21$ decibel $(\mathrm{dB})$, final $\mathrm{MD}$ was $-9.42 \pm 5.32 \mathrm{~dB}$, number of VF tests was $12.8 \pm 2.7$ times, and the follow-up period was $7.6 \pm 2.0$ years.

A significant deterioration of MD slope was observed in 70 eyes of 70 patients in the MD slope deteriorating

Table I Patients' characteristics

\begin{tabular}{|c|c|}
\hline Number of subjects & I 56 eyes of I 56 patients \\
\hline Age (years) & $64.6 \pm 12.9$ (28 to 88$)$ \\
\hline \multicolumn{2}{|l|}{ Sex, n (\%) } \\
\hline Female & $94(60.3)$ \\
\hline Male & $62(39.7)$ \\
\hline \multicolumn{2}{|l|}{ Type of glaucoma, n (\%) } \\
\hline NTG & |4| (90.4) \\
\hline POAG & $15(9.6)$ \\
\hline Baseline refraction (D) & $-2.8 \pm 3.7(-16$ to +2.5$)$ \\
\hline Baseline IOP (mmHg) & I6.6 \pm 3.7 (8.0 to 28.6$)$ \\
\hline Initial MD value $(\mathrm{dB})$ & $-7.08 \pm 4.21(-18.39$ to +0.03$)$ \\
\hline Final MD value $(\mathrm{dB})$ & $-9.42 \pm 5.32(-25.49$ to +0.67$)$ \\
\hline Number of visual field & $12.8 \pm 2.7(10$ to 25$)$ \\
\hline \multicolumn{2}{|l|}{ examinations (times) } \\
\hline Follow-up duration (years) & $7.6 \pm 2.0(4.5$ to 16.5$)$ \\
\hline
\end{tabular}

Notes: Data are $\mathrm{n}(\%)$ or mean \pm SD (range); NTG was defined as baseline $I O P \leq 21 \mathrm{mmHg}$; POAG was defined as baseline IOP $>21 \mathrm{mmHg}$; Baseline IOP was determined by averaging first three measurements taken with Goldmann applanation tonometer before initiation of therapy. Copyright (c) 2015. Dove Medical Press. Reproduced from Naito T, Yoshikawa K, Mizoue S, et al. Relationship between progression of visual field defect and intraocular pressure in primary open-angle glaucoma. Clin Ophthalmol. 2015;9:1373-1378. ${ }^{25}$

Abbreviations: $D$, diopter; IOP, intraocular pressure; MD, mean deviation; $\mathrm{dB}$, decibel; NTG, normal-tension glaucoma; POAG, primary open-angle glaucoma; $\mathrm{SD}$, standard deviation. group (MD slope deteriorating group, 44.9\%), whereas no significant deterioration was evident in 86 eyes of 86 patients in the MD slope nondeteriorating group, 55.1\% (Table 2). ${ }^{25}$ In the MD slope deteriorating group, age $(66.9 \pm 11.3 \mathrm{vs}$ $62.6 \pm 13.9$ years, $P=0.0370$ ), proportion of female patients (49 vs 45 patients, $P=0.0324$ ), and baseline refraction $(-1.9 \pm 3.8$ vs $-3.5 \pm 3.4 \mathrm{D}, P=0.0048)$ were significantly higher compared to the MD slope nondeteriorating group. However, there were no significant differences between the two groups in terms of initial MD value $(-6.60 \pm 4.17$ vs $-7.48 \pm 4.23 \mathrm{~dB}, P=0.1916)$.

The proportion of eyes with and without MD slope deterioration in each baseline refractive category is shown in Figure 1. The Cochran-Armitage trend analysis showed a decreasing trend in the proportion of MD slope deterioration with the increasing severity of myopia (from $62.9 \%$ to $30.0 \%, P=0.0002)$. In addition to the baseline refraction, one-way analysis of variance showed that age $(P=0.0370)$ and IOP reduction rate $(P=0.0066)$ were also factors related to MD slope deterioration. Moreover, the rate of hyperopia significantly increased with age $(P<0.0001)$, but a correlation between baseline refraction and IOP reduction rate was not found to be evident $(P=0.1044$; one-way analysis of variance). Using sex, baseline refraction, IOP reduction rate, minimum IOP, and long-term IOP fluctuation, all of which showed cross-correlation coefficients less than 0.3 (Table 2), multiple logistic regression analysis was performed by selecting variables in a stepwise method. The result showed that baseline refraction $(P=0.0108$, OR: 1.13 , 95\% CI: $1.03-1.25)$ and IOP reduction rate $(P=0.0150, \mathrm{OR}$ : 0.97, 95\% CI: 0.94-0.99) were variables significantly associated with MD slope deterioration (Table 3).

A comparison of IOP factors between the MD slope deteriorating and nondeteriorating group revealed no obvious differences in mean IOP $(13.2 \pm 2.2$ vs $13.5 \pm 2.1 \mathrm{mmHg}$, $P=0.3992)$ and maximum IOP (16.9 \pm 3.8 vs $16.7 \pm 3.0 \mathrm{mmHg}$, $P=0.8147$ ) during the follow-up, but there were significant differences between the two groups in terms of baseline IOP $(15.7 \pm 3.6$ vs $17.2 \pm 3.6 \mathrm{mmHg}, P=0.0107)$, IOP reduction rate $(14.9 \% \pm 13.0 \%$ vs $20.3 \% \pm 11.8 \%, P=0.0066)$, minimum IOP (10.2 \pm 2.1 vs $11.0 \pm 2.0 \mathrm{mmHg}, P=0.0161)$, and long-term IOP fluctuation ( $1.7 \pm 0.9$ vs $1.4 \pm 0.5 \mathrm{mmHg}, P=0.0309)$ during the follow-up (Table 2). ${ }^{25}$

\section{Discussion}

IOP is consistently the major risk factor for the progression of OAG. ${ }^{28-31}$ Our previous analysis of Japanese patients with POAG, including $\mathrm{NTG}^{25}$ also resulted in a significant association between IOP-related factors (OR: 0.97, 95\% CI: 
Table 2 Associations between different factors and MD slope deterioration

\begin{tabular}{|c|c|c|c|}
\hline \multirow[t]{2}{*}{ Clinical variables } & \multicolumn{2}{|l|}{ MD slope } & \multirow[t]{2}{*}{$P$-value ${ }^{a}$} \\
\hline & $\begin{array}{l}\text { Deteriorating group } \\
(n=70)\end{array}$ & $\begin{array}{l}\text { Nondeteriorating group } \\
(\mathrm{n}=86)\end{array}$ & \\
\hline Age (years) & $66.9 \pm 11.3$ & $62.6 \pm 13.9$ & $0.0370 *$ \\
\hline \multicolumn{4}{|l|}{ Sex, n (\%) } \\
\hline Female & $49(70.0)$ & $45(52.3)$ & $0.0324^{*}$ \\
\hline Male & $21(30.0)$ & $4 I(47.7)$ & \\
\hline Baseline refraction $(D)$ & $-1.9 \pm 3.8$ & $-3.5 \pm 3.4$ & $0.0048^{*}$ \\
\hline Initial MD value $(\mathrm{dB})$ & $-6.60 \pm 4.17$ & $-7.48 \pm 4.23$ & 0.1916 \\
\hline MD slope (dB/year) & $-0.7 I \pm 0.45$ & $-0.0 \mathrm{I} \pm 0.28$ & $<0.0001 *$ \\
\hline Baseline IOP $(\mathrm{mmHg})$ & $15.7 \pm 3.6$ & $17.2 \pm 3.6$ & $0.0107 *$ \\
\hline IOP over follow-up (mmHg) & $13.2 \pm 2.2$ & $13.5 \pm 2.1$ & 0.3992 \\
\hline IOP reduction rate (\%) & $14.9 \pm 13.0$ & $20.3 \pm 11.8$ & $0.0066^{*}$ \\
\hline Maximum IOP $(\mathrm{mmHg})$ & $16.9 \pm 3.8$ & $16.7 \pm 3.0$ & 0.8147 \\
\hline Minimum IOP $(\mathrm{mmHg})$ & $10.2 \pm 2.1$ & $11.0 \pm 2.0$ & $0.0161 *$ \\
\hline Long-term IOP fluctuation $(\mathrm{mmHg})$ & $1.7 \pm 0.9$ & $1.4 \pm 0.5$ & $0.0309 *$ \\
\hline
\end{tabular}

Notes: Data are mean \pm SD or $\mathrm{n}(\%)$; Long-term IOP fluctuation was calculated as the SD of IOP measurements over the follow-up period; at-test except sex (Fisher's exact test). *Statistically significant. Copyright @ 2015. Dove Medical Press. Reproduced from Naito T, Yoshikawa K, Mizoue S, et al. Relationship between progression of visual field defect and intraocular pressure in primary open-angle glaucoma. Clin Ophthalmol. 2015;9:1373-1378. ${ }^{25}$

Abbreviations: D, diopter; dB, decibel; IOP, intraocular pressure; MD, mean deviation; NTG, normal-tension glaucoma; POAG, primary open-angle glaucoma; SD, standard deviation.

0.94-0.99 for IOP reduction rate; OR: $1.87,95 \%$ CI: $1.13-3.38$ for long-term IOP fluctuation) and further MD slope deterioration. Although several studies indicated that myopia may play a role in VF progression in OAG eyes, ${ }^{1-12}$ there has been controversy regarding the relationship between myopia and the development of VF defects in $\mathrm{OAG} .{ }^{13-21} \mathrm{We}$, therefore, analyzed the association between baseline refraction and $\mathrm{VF}$ progression employing our previous data of POAG; most of the subjects had NTG (90.4\%) and more than a half of them had myopia $(60.3 \%){ }^{25}$

In the current analysis, baseline refraction (per 1D, OR: $1.13,95 \%$ CI: $1.03-1.25, P=0.0108)$ as well as IOP reduction rate (per 1\%, OR: $0.97,95 \%$ CI: 0.94-0.99, $P=0.0150$ ) were observed to be significantly associated with

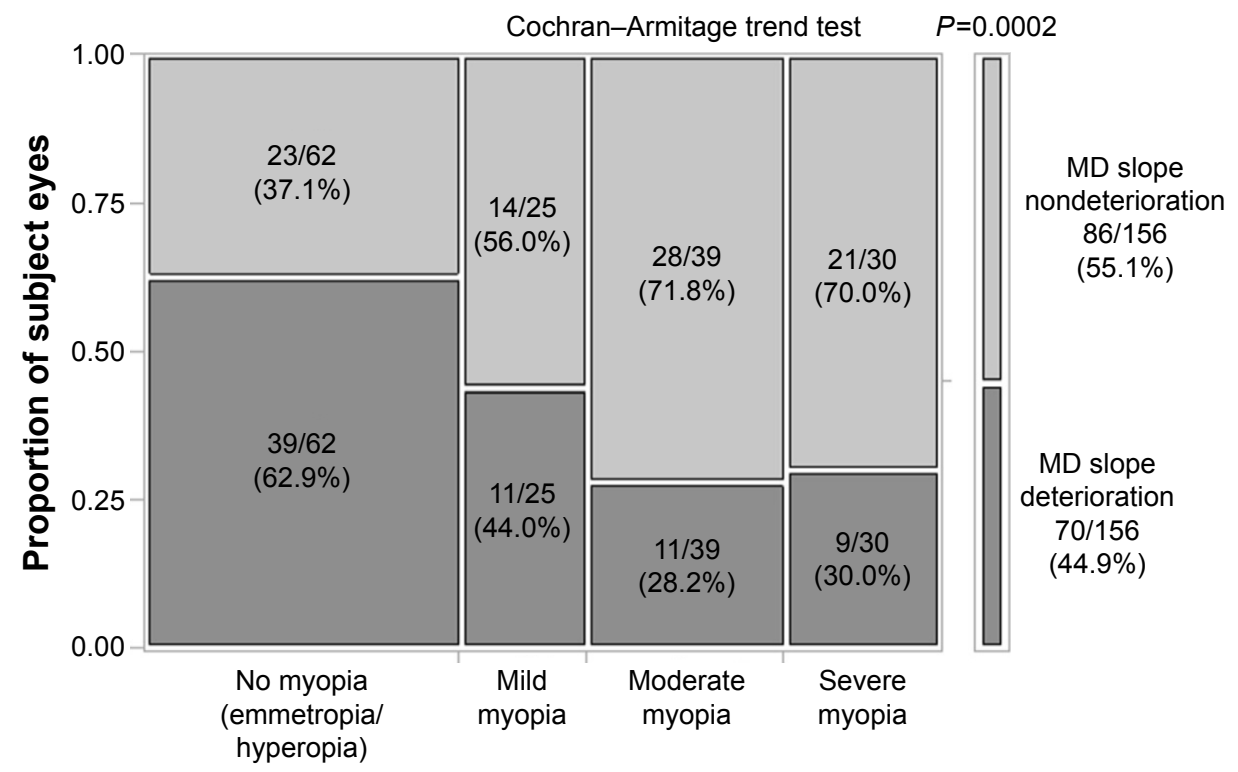

Baseline refractive status by category

Figure I Proportion of eyes with MD slope deterioration or nondeterioration in each refractive category.

Notes: Data are n (\%); Myopia was divided into four categories based on SE: emmetropia/hyperopia (SE $>-I D)$, mild myopia $(-I D \geq S E>-3 D)$, moderate myopia $(-3 D \geq S E>-6 D)$, and severe myopia $(-6 D \geq S E)$.

Abbreviations: $M D$, mean deviation; SE, spherical equivalent; $D$, diopter. 
Table 3 Multivariate analysis for prediction of MD slope deterioration

\begin{tabular}{lll}
\hline Factors & Odds ratio (95\% CI) & $P$-value \\
\hline Baseline refraction (per ID) & I.13 (I.03-I.25) & $0.0108 *$ \\
IOP reduction rate (per I\%) & $0.97(0.94-0.99)$ & $0.0150 *$ \\
\hline
\end{tabular}

Notes: Baseline refraction and IOP reduction rate treated as explanatory variables. MD slope deterioration treated as objective variable. Odds ratios were the values with each ID increase (ID shift toward hyperopia) in baseline refraction or with each $1 \%$ increase (I\% greater rate) in IOP reduction rate. *Statistical significance.

Abbreviations: $\mathrm{D}$, diopter; $\mathrm{Cl}$, confidence interval; IOP, intraocular pressure; MD, mean deviation.

MD slope deterioration. Additionally, we found a decreasing trend in the proportion of MD slope deterioration with the increasing severity of myopia $(P=0.0002)$. Less extent of myopia was a significant risk factor for VF progression.

Araie et $\mathrm{al}^{20}$ reported that less extent of myopia was a significant risk factor (per 1D, hazard ratio: $1.17,95 \% \mathrm{CI}$ : $1.01-1.35, P=0.038$ ) for VF progression in treated NTG where most patients had mild myopia and IOP during follow-up, which averaged $13.2 \mathrm{mmHg}$. The results of the present study, in which patients were observed for a relatively longer period of time (mean follow-up of 7.6 years) compared to other studies ${ }^{16-21}$ seem to confirm that myopia was not a significant risk factor for VF progression in our POAG population.

Optic discs in highly myopic eyes are thought to be more vulnerable to mechanical insult than nonmyopic ones; therefore, it was rather unexpected that higher myopia was not associated with a higher risk of VF progression in POAG. ${ }^{13,15,32} \mathrm{In}$ highly myopic eyes, structural changes such as elongated axial length, tilted optic disc, parapapillary atrophy, and thinning of the lamina cribrosa and parapapillary sclera ${ }^{33,34}$ can cause VF defects..$^{35}$ The myopia-related structural changes may be more pronounced if glaucoma is present. Thus, some myopic eyes with VF defects tend to be misdiagnosed as NTG, and this could have led to the conclusion of a negative association between the severity of myopia and VF progression. We, therefore, carefully recruited and analyzed subjects with typical glaucomatous VF changes in accordance with Anderson's criteria $^{26}$ to exclude the eyes with myopic VF defects.

Although the pathophysiological mechanism of the impact of myopia on VF progression in OAG is still unknown, one possible hypothesis is that the difference of axial length might positively affect IOP fluctuation. ${ }^{36,37}$ Axial length is one of the major factors contributing to myopia. Loewen et al ${ }^{38}$ reported that basal 24-hour habitual IOP fluctuation was negatively correlated with axial length in a comparison of healthy adults with hyperopia, emmetropia, and myopia. Although there were posture-dependent and -independent mechanisms for the fluctuation, hyperopic eyes with a shorter axial length had a larger 24-hour IOP variation. Jeong et $\mathrm{a}^{36}$ reported that POAG eyes with moderate/severe myopia $(-6.78 \mathrm{D}$, axial length: $26.47 \mathrm{~mm}$ ) had a lower acrophase in the circadian IOP and a smaller range of 24-hour IOP fluctuation as compared to POAG eyes with emmetropia/mild myopia ( $-0.74 \mathrm{D}$, axial length: $23.55 \mathrm{~mm})$. Qiu et $\mathrm{a}^{37}$ reported that longer axial length was associated with a smaller chance for VF progression in POAG. In this study, although we could not collect data of axial length, all subject eyes were phakic. As myopia becomes more severe, the axial length of the eye generally increases. In studies with animal models, axial myopia is structurally characterized by reduction of collagen fiber bundles and the size of individual collagen fibrils within the sclera as well as thinning of sclera, resulting in low scleral rigidity. ${ }^{39,40}$ This low scleral rigidity may result in more extensile intrascleral and episcleral venous system in myopic eyes, leading to less episcleral venous pressure elevation with increased aqueous outflow, and smaller range of short-term IOP fluctuation, when compared to emmetropic/ hyperopic eyes during posture change.

Our study design was multicenter and retrospective in nature, and short-term IOP fluctuation was not studied. However, long-term IOP fluctuation, which was defined as the standard deviation of IOP during follow-up, might be a significant risk factor with MD slope deterioration (per $1 \mathrm{mmHg}$, OR: 1.87, 95\% CI: 1.13-3.38). ${ }^{25}$ Several studies $^{41-44}$ reported that long-term IOP fluctuation is a risk factor for VF progression. The Advanced Glaucoma Intervention Study ${ }^{42}$ found that with each $1 \mathrm{mmHg}$ increase in IOP fluctuation, the odds of VF progression increased by approximately $30 \%$ in OAG patients who had larger IOP fluctuation. Fukuchi et a ${ }^{43}$ reported that NTG patients with fast VF progression showed larger long-term IOP fluctuation than those with slow progression, but these correlations were not seen in POAG patients. Simultaneously, it should be noted that the relationship between IOP fluctuation and VF progression may differ depending on the magnitude of IOP, because it has been suggested that IOP fluctuation has a greater impact on progression in eyes with low IOP. ${ }^{44}$ Our study showed that the majority of the subjects were NTG patients in whom average IOP was $16.6 \mathrm{mmHg}$, and so, if a large number of patients with higher IOP that exceeded $21 \mathrm{mmHg}$ were included, the results could have been different, and it is conceivable that less cumulative IOP insults in myopic eyes might prevent optic nerve injury for glaucoma. Even though POAG is a multifactorial disease, patients with higher level of IOP are at greater risk of damage to their 
optic nerve head, and IOP reduction may contribute more to prevent VF progression than small IOP fluctuations as well as other disease-associated factors. This may partly explain the reason the relationship between myopia and VF progression in OAG is overly complicated.

There are some limitations and strengths in this study. Since the study design was retrospective, short-term IOP fluctuation was not analyzed, and other possible existing factors associated with VF progression were not fully explored. In addition, it may be argued that the relatively small number of patients in each of the myopic categories may lead to lack of statistical power. To validate the current results, future prospective studies with longer follow-up periods are necessary to elucidate the causative relationship between myopia and VF progression in POAG. Furthermore, it has been previously reported that disc hemorrhage was an indispensable risk factor in VF progression. ${ }^{45}$ Disc hemorrhage may be a sign of the local vascular abnormalities that tends to be associated with NTG. ${ }^{46}$ Although a majority of the subject eyes had NTG (90.4\%, 141/156 eyes) in this study, we unfortunately could not have sufficient data of disc hemorrhage, because this was not a study designed prospectively.

\section{Conclusion}

In conclusion, the current analysis of Japanese patients with POAG indicated that myopia would not cause VF progression. Meanwhile, hyperopia could lead to the occurrence of MD slope deterioration.

\section{Acknowledgment}

The authors wish to thank Nobuko Fujita for her help in preparing this manuscript.

\section{Disclosure}

The authors report no conflicts of interest in this work.

\section{References}

1. Shen L, Melles RB, Metlapally R, et al. The association of refractive error with glaucoma in a multiethnic population. Ophthalmology. 2016; 123(1):92-101.

2. Chon B, Qiu M, Lin SC. Myopia and glaucoma in the South Korean population. Invest Ophthalmol Vis Sci. 2013;54:6570-6577.

3. Qiu M, Wang SY, Singh K, Lin SC. Association between myopia and glaucoma in the United States population. Invest Ophthalmol Vis Sci. 2013; 54(1):830-835.

4. Marcus MW, de Vries MM, Junoy Montolio FG, Jansonius NM. Myopia as a risk factor for open-angle glaucoma: a systematic review and metaanalysis. Ophthalmology. 2011;118(10):1989-1994.e2.

5. Kuzin AA, Varma R, Reddy HS, Torres M, Azen SP; Los Angeles Latino Eye Study Group. Ocular biometry and open-angle glaucoma: the Los Angeles Latino Eye Study. Ophthalmology. 2010;117(9):1713-1719.
6. Perera SA, Wong TY, Tay WT, Foster PJ, Saw SM, Aung T. Refractive error, axial dimensions, and primary open-angle glaucoma: the Singapore Malay Eye Study. Arch Ophthalmol. 2010;128(7):900-905.

7. Xu L, Wang Y, Wang S, Wang Y, Jonas JB. High myopia and glaucoma susceptibility the Beijing Eye Study. Ophthalmology. 2007;114(2): 216-220.

8. Suzuki Y, Iwase A, Araie M, et al; Tajimi Study Group. Risk factors for open-angle glaucoma in a Japanese population: the Tajimi Study. Ophthalmology. 2006;113(9):1613-1617.

9. Ramakrishnan R, Nirmalan PK, Krishnadas R, et al. Glaucoma in a rural population of southern India: the Aravind comprehensive eye survey. Ophthalmology. 2003;110(8):1484-1490.

10. Wong TY, Foster PJ, Hee J, et al. Prevalence and risk factors for refractive errors in adult Chinese in Singapore. Invest Ophthalmol Vis Sci. 2000; 41(9):2486-2494.

11. Mitchell P, Hourihan F, Sandbach J, Wang JJ. The relationship between glaucoma and myopia: the Blue Mountains Eye Study. Ophthalmology. 1999;106(10):2010-2015.

12. Wu SY, Nemesure B, Leske MC. Refractive errors in a black adult population: the Barbados Eye Study. Invest Ophthalmol Vis Sci. 1999;40(10): 2179-2184.

13. Chihara E, Liu X, Dong J, et al. Severe myopia as a risk factor for progressive visual field loss in primary open-angle glaucoma. Ophthalmologica. 1997;211(2):66-71.

14. Perdicchi A, Iester M, Scuderi G, Amodeo S, Medori EM, Recupero SM. Visual field damage and progression in glaucomatous myopic eyes. Eur J Ophthalmol. 2007;17(4):534-537.

15. Lee YA, Shih YF, Lin LL, Huang JY, Wang TH. Association between high myopia and progression of visual field loss in primary open-angle glaucoma. J Formos Med Assoc. 2008;107(12):952-957.

16. Doshi A, Kreidl KO, Lombardi L, Sakamoto DK, Singh K. Nonprogressive glaucomatous cupping and visual field abnormalities in young Chinese males. Ophthalmology. 2007;114(3):472-479.

17. Ishida K, Yamamoto T, Kitazawa Y. Clinical factors associated with progression of normal-tension glaucoma. J Glaucoma. 1998;7(6): 372-377.

18. Araie M, Sekine M, Suzuki Y, Koseki N. Factors contributing to the progression of visual field damage in eyes with normal-tension glaucoma. Ophthalmology. 1994;101(8):1440-1444.

19. Sakata R, Aihara M, Murata $\mathrm{H}$, et al. Contributing factors for progression of visual field loss in normal-tension glaucoma patients with medical treatment. J Glaucoma. 2013;22(3):250-254.

20. Araie M, Shirato S, Yamazaki Y, Matsumoto C, Kitazawa Y, Ohashi Y; Nipradilol-Timolol Study Group. Risk factors for progression of normaltension glaucoma under $\beta$-blocker monotherapy. Acta Ophthalmol. 2012;90(5):e337-e343.

21. Phelps CD. Effect of myopia on prognosis in treated primary open-angle glaucoma. Am J Ophthalmol. 1982;93(5):622-628.

22. Iwase A, Suzuki Y, Araie M, et al; Tajimi Study Group, Japan Glaucoma Society. The prevalence of primary open-angle glaucoma in Japanese: the Tajimi Study. Ophthalmology. 2004;111(9):1641-1648.

23. Yamamoto T, Iwase A, Araie M, et al; Tajimi Study Group, Japan Glaucoma Society. The Tajimi Study report 2: prevalence of primary angle closure and secondary glaucoma in a Japanese population. Ophthalmology. 2005;112(10):1661-1669.

24. Sawada A, Tomidokoro A, Araie M, Iwase A, Yamamoto T; Tajimi Study Group. Refractive errors in an elderly Japanese population: the Tajimi study. Ophthalmology. 2008;115(2):363-370.e3.

25. Naito T, Yoshikawa K, Mizoue S, et al. Relationship between progression of visual field defect and intraocular pressure in primary open-angle glaucoma. Clin Ophthalmol. 2015;9:1373-1378.

26. Anderson DR, Patella VM. Automated Static Perimetry. 2nd ed. St Louis, MO: Mosby; 1999:121-190.

27. [Japan Glaucoma Society. The Japan Glaucoma Society Guidelines for Glaucoma (3rd ed.)]. Nihon Ganka Gakkai Zasshi. 2012;116(1):3-46. Japanese. 
28. Heijl A, Leske MC, Bengtsson B, Hyman L, Bengtsson B, Hussein M; Early Manifest Glaucoma Trial Group. Reduction of intraocular pressure and glaucoma progression: results from the Early Manifest Glaucoma Trial. Arch Ophthalmol. 2002;120(10):1268-1279.

29. Leske MC, Heijl A, Hussein M, Bengtsson B, Hyman L, Komaroff E; Early Manifest Glaucoma Trial Group. Factors for glaucoma progression and the effect of treatment: the early manifest glaucoma trial. Arch Ophthalmol. 2003;121(1):48-56.

30. Leske MC, Heijl A, Hyman L, Bengtsson B, Dong L, Yang Z; EMGT Group. Predictors of long-term progression in the early manifest glaucoma trial. Ophthalmology. 2007;114(11):1965-1972.

31. Drance S, Anderson DR, Schulzer M; Collaborative Normal-Tension Glaucoma Study Group. Risk factors for progression of visual field abnormalities in normal-tension glaucoma. Am J Ophthalmol. 2001 131(6):699-708.

32. Kimura Y, Akagi T, Hangai M, et al. Lamina cribrosa defects and optic disc morphology in primary open angle glaucoma with high myopia. PLoS One. 2014;9(12):e115313.

33. Tay E, Seah SK, Chan SP, et al. Optic disk ovality as an index of tilt and its relationship to myopia and perimetry. Am J Ophthalmol. 2005; 139(2):247-252.

34. Jonas JB, Berenshtein E, Holbach L. Lamina cribrosa thickness and spatial relationships between intraocular space and cerebrospinal fluid space in highly myopic eyes. Invest Ophthalmol Vis Sci. 2004;45(8): 2660-2665.

35. Ohno-Matsui K, Shimada N, Yasuzumi K, et al. Long-term development of significant visual field defects in highly myopic eyes. Am J Ophthalmol. 2011;152(2):256-265.e1.

36. Jeong da W, Kook MS, Lee KS, Lee JR, Han S. Circadian pattern of intraocular pressure fluctuations in young myopic eyes with open-angle glaucoma. Invest Ophthalmol Vis Sci. 2014;55(4):2148-2156.
37. Qiu C, Qian S, Sun X, Zhou C, Meng F. Axial myopia is associated with visual field prognosis of primary open-angle glaucoma. PLoS One. 2015;10(7):e0133189.

38. Loewen NA, Liu JH, Weinreb RN. Increased 24-hour variation of human intraocular pressure with short axial length. Invest Ophthalmol Vis Sci. 2010;51(2):933-937.

39. McBrien NA, Cornell LM, Gentle A. Structural and ultrastructural changes to the sclera in a mammalian model of high myopia. Invest Ophthalmol Vis Sci. 2001;42(10):2179-2187.

40. McBrien NA, Norton TT. Prevention of collagen crosslinking increases form-deprivation myopia in tree shrew. Exp Eye Res. 1994; 59(4):475-486.

41. Komori S, Ishida K, Yamamoto T. Results of long-term monitoring of normal-tension glaucoma patients receiving medical therapy: results of an 18-year follow-up. Graefes Arch Clin Exp Ophthalmol. 2014; 252(12):1963-1970.

42. Nouri-Mahdavi K, Hoffman D, Coleman AL, et al; Advanced Glaucoma Intervention Study. Predictive factors for glaucomatous visual field progression in the Advanced Glaucoma Intervention Study. Ophthalmology. 2004;111(9):1627-1635.

43. Fukuchi T, Yoshino T, Sawada H, et al. The relationship between the mean deviation slope and follow-up intraocular pressure in open-angle glaucoma patients. J Glaucoma. 2013;22(9):689-697.

44. Caprioli J. Intraocular pressure fluctuation: an independent risk factor for glaucoma? Arch Ophthalmol. 2007;125(8):1124-1125.

45. Ernest PJ, Schouten JS, Beckers HJ, Hendrikse F, Prins MH, Webers CA. An evidence-based review of prognostic factors for glaucomatous visual field progression. Ophthalmology. 2013;120(3):512-519.

46. Shields MB. Normal-tension glaucoma: is it different from primary open-angle glaucoma? Curr Opin Ophthalmol. 2008;19(2):85-88.
Clinical Ophthalmology

\section{Publish your work in this journal}

Clinical Ophthalmology is an international, peer-reviewed journal covering all subspecialties within ophthalmology. Key topics include: Optometry; Visual science; Pharmacology and drug therapy in eye diseases; Basic Sciences; Primary and Secondary eye care; Patient Safety and Quality of Care Improvements. This journal is indexed on

\section{Dovepress}

PubMed Central and CAS, and is the official journal of The Society of Clinical Ophthalmology (SCO). The manuscript management system is completely online and includes a very quick and fair peer-review system, which is all easy to use. Visit http://www.dovepress.com/ testimonials.php to read real quotes from published authors. 